\title{
A EDUCAÇÃO EM REDE EM ÉPOCA DE PANDEMIA NO ESTADO NEOLIBERAL BRASILEIRO: POR UMA VIDA MAIS SOLIDÁRIA E DE ACOLHIMENTO, PARA AS EPIDEMIAS E CRISES SE REPETIREM MENOS!
}

\author{
Nestor Francisco Rambo ${ }^{1}$
}

\section{Resumo:}

Em tempos de pandemia, quando pensamos na superação da crise, é preciso uma responsabilidade no conjunto da sociedade. Os Estados, escolas, empresas, sindicatos e universidades precisam (re)pensar estratégias de cooperação entre os homens. No Estado moderno o sujeito reconhecido como cidadão, encontra-se em crise. A idealização universal do "ser cidadão" encontra-se fragilizada, rompida da sua existência como ser humano. Nos currículos escolares será necessária a ênfase para uma educação voltada para a sustentabilidade, pois o aquecimento global e a economia não solidária, não comunitária, do desperdício, e, não distributiva, vai definhando com o planeta. $\mathrm{O}$ desemprego e a fome aumentaram no mundo. São necessárias formas associativas de trabalho. Com o Novo FUNDEB, existe a possibilidade do salário do professor da Educação Básica no Brasil ser mais justo, com a observância da Lei do Piso do Professor e Planos de Carreira, que contemplem os diferentes níveis de formação e formação contínua. Com salários mais dignos e justos aos professores, ganha a sociedade, e aprimora-se a ciência, a tecnologia e a pesquisa. Ganha a educação em qualidade, com profissionais mais motivados. O capitalismo neoliberal em curso no Brasil e em outras partes do mundo, exercem uma forte pressão sobre os nossos currículos escolares. A mentira que vale como verdade, e a verdade que vale como mentira, como parte da cultura neoliberal, desestruturam as famílias, crianças, os jovens, a classe trabalhadora e os professores. É chegado o momento que almejamos, um mundo pós-pandemia, mais fraterno, solidário e cooperativo. Na educação, o professor é um dos profissionais mais vulneráveis ao Covid-19, e, diante desse quadro, as aulas presenciais não devem reiniciar no presente ano, ou, enquanto não for descoberto a cura da doença. O professor voltará mais valorizado pelas famílias, pela dimensão da complexidade que envolveu os pais em lidarem com os filhos nas tarefas escolares. Urge, que o Estado, o MEC e os políticos valorizem o professor com melhores condições de trabalho e salário. A responsabilidade e a solidariedade, são dimensões inseparáveis da ética. Se me sinto responsável, também me sinto solidário.

Palavras-chave: Estado, cidadania, globalização, solidariedade, pandemia, educação.

\section{NETWORK EDUCATION IN THE TIME OF PANDEMIC IN THE BRAZILIAN NEOLIBERAL STATE: FOR A MORE SOLIDARY AND WELCOME LIFE, LESS PEOPLE REPEAT FOR EPIDEMICS AND CRISES!}

\author{
Nestor Francisco Rambo
}

\begin{abstract}
:
In times of pandemic, when we think about overcoming the crisis, there is a need for responsibility in society as a whole. States, schools, companies, unions and universities need to (re) think strategies for cooperation between men. In the modern state, the subject recognized as a citizen is in crisis. The universal idealization of "being a citizen" is weakened, broken from its existence as a human being. In school curricula, an emphasis on education focused on sustainability will be necessary, as global warming and the non-supportive, non-community economy of waste, and, non-distributive, will languish with the planet. Unemployment and hunger have increased worldwide. Associative forms of work are needed. With the New FUNDEB, there is a possibility that the basic

1 Doutor em Geografia, com ênfase no Ensino, Território e Ambiente (UFRGS); Mestre em Geografia, com ênfase no Ensino, Território e Ambiente (UFRGS); Especialização em Geografia Regional (Unochapecó); Geografia (Unochapecó); Estudos Sociais (Unisinos); Ex-Bolsista da FAPESC; Professor na Rede Pública Estadual de Santa Catarina (32 anos); Professor Universitário (11 anos); Co-autor de Diretrizes 3 - Organização da Prática Escolar na Educação Básica do Território Catarinense (2001), Co-autor da Proposta Curricular de Santa Catarina (2014); Co-autor da BNCC - Currículo Base da Educação Infantil do Ensino Fundamental do Território Catarinense (2019); Co-autor da BNCC - Ensino Médio do Território Catarinense (2020), em elaboração. E-mail: nestorfranciscorambo@yahoo.com.br
\end{abstract}


education teacher's salary in Brazil is fairer, with the observance of the Teacher's Floor Law and Career Plans, which contemplate the different levels of training and continuing education. With more dignified and fair salaries for teachers, society gains, and science, technology and research are improved. Quality education wins, with more motivated professionals. Neoliberal capitalism underway in Brazil and in other parts of the world, puts a strong pressure on our school curricula. The lie that counts as a truth, and the truth that counts as a lie, as part of neoliberal culture, disrupt families, children, young people, the working class and teachers. The time has come for a postpandemic world that is more fraternal, supportive and cooperative. In education, the teacher is one of the professionals most vulnerable to Covid-19, and, given this situation, face-to-face classes should not restart this year, or, until the cure for the disease has been discovered. The teacher will come back more valued by families, due to the dimension of the complexity that involved parents in dealing with their children in school tasks. It is urgent that the State, the MEC and the politicians value the teacher with better working conditions and salary. Responsibility and solidarity are inseparable dimensions of ethics. If I feel responsible, I also feel supportive.

Keywords: State, citizenship, globalization, solidarity, pandemic, education.

\section{Introdução}

A atual crise da Covid-19, que parou a maioria das escolas, universidades e modificou a postura da maioria das organizações institucionais no Brasil e no mundo, ensinou e mostrou ao mundo, que a sustentabilidade do planeta está chegando ao limite.

O isolamento social das famílias e da sociedade, permitiu perceber que para a superação da doença, das dificuldades, da pandemia, da crise da Covid-19, e, de inúmeros outros problemas dela decorrentes, que não adianta falarmos em "superação da crise", se não pensarmos e nos responsabilizarmos pelo conjunto da sociedade. Nunca a sociedade, os Estados, as escolas, as universidades e as empresas tiveram que (re)pensar novas estratégias de cooperação entre os homens. Ou o mundo pensa em novas estratégias de cooperação, numa vida mais solidária e de fraternidade, caso contrário, as epidemias e crises se repetirão numa escala (temporária) cada vez menor. O autor (Chagas, 2012, p.43), chama a atenção com seus estudos e análises a partir de Marx, a problemática da fragmentação humana no mundo, afirmando que,

No Estado moderno, a universalidade, a genericidade, localiza-se na cidadania, nos direitos humanos, mas não permite ao sujeito fragmentado reencontrar a sua unidade, pois a universalidade presente não é concreta, efetiva, mas abstrata, formal. No Estado moderno, o sujeito é reconhecido como cidadão, como um ser universal, mas esta idealidade universal está separada, abstraída, de sua existência real e particular.

Nos currículos escolares será necessária a ênfase para uma educação voltada para a sustentabilidade, pois o aquecimento global e a economia não solidária, não comunitária, do

\begin{tabular}{|l|c|c|c|c|}
\hline Qevista Dialectus & Ano 9 & n. 19 & Agosto-Dezembro 2020 & p. $239-255$ \\
\hline
\end{tabular}


desperdício, e, não distributiva, vai definhando com o planeta. O desemprego e a fome aumentaram no mundo. Assim sendo, deve tornar-se senso comum, com uma nova cultura e tomada de postura, em preservar-se o meio ambiente, a água, as florestas, a ictiofauna, os biomas e a preservação da vida animal.

A atual crise da pandemia deve servir como alerta e preparo para outras que virão num futuro próximo. A geografia da população mundial cresceu muito. A China está contabilizando 1,4 bilhão de pessoas. A Índia, contabiliza 1,3 bilhão de pessoas. A África Subsaariana, não consegue sequer matar a fome das crianças, muito menos fazer uma campanha de natalidade. Neste patamar de somatórios, contabilidades e mensuras, nada animadores para a sustentabilidade do planeta, a escola e a educação ganham relevância para o "sonho de viver bem”, conforme salienta Gadotti (2009, p.14). Além disso, Gadotti (2009, p. 14), ensina-nos, que sustentabilidade "é equilíbrio dinâmico com o outro e com o meio ambiente, é harmonia entre os diferentes". Eis que se clama por uma vida mais justa, solidária e para todos.

Em épocas de crise e de pandemia como a de agora, no presente ano de 2020, mais do que nunca precisamos despertar para uma educação voltada para a "economia solidária", regida pelos princípios, que são no dizer de Gadotti (2009, p. 150), constituídos pela "solidariedade, liberdade, da inclusão social e da emancipação". Devemos voltar nossos currículos e nos concentrar numa educação voltada para a cooperação.

Neste tempo de pandemia, a educação teve que reinventar-se, amoldar-se e até aperfeiçoar-se a uma nova cultura, baseada no "informacional" num mundo conectado em redes. Para Castells (2009, p. 141), o mundo informacional possui aspectos bons e menos bons, ao afirmar que,

\footnotetext{
portanto, o resultado líquido do primeiro estágio da revolução informacional traduziuse em vantagens e desvantagens para o progresso econômico. Além disso, a generalização da produção e da administração baseadas em conhecimentos para toda a esfera de processos econômicos em escala global requer transformações sociais, culturais institucionais básicas que, se considerarmos o registro histórico de outras revoluções tecnológicas, levarão um certo tempo. É por isso que a economia é informacional, e não apenas baseada na informação, pois os atributos culturais e institucionais de todo o sistema social devem ser incluídos na implementação e difusão do novo paradigma tecnológico.
}

Como lado nefasto, do atual estágio da globalização, percebemos a perda e a desvalorização de símbolos humanos, do currículo escolar, presentes em discussões

\begin{tabular}{|l|l|l|l|l|}
\hline Q & Anista & n. 19 & Agosto - Dezembro 2020 & p. $239-255$ \\
\hline
\end{tabular}


importantes da BNCC, nos Estados do Território Brasileiro. Valores importantes da vida humana, como liberdade, cooperação, solidariedade, saúde baseada na ciência e na vida, são ridicularizados. O capitalismo neoliberal em curso no Brasil e em outras partes do mundo, exercem uma forte pressão sobre os nossos currículos escolares. A mentira que vale como verdade, e a verdade que vale como mentira, como parte da cultura neoliberal, desestruturam as famílias, crianças, os jovens, a classe trabalhadora, a Justiça, o Estado e a Igreja (como instituição). O estudioso e Jurista Casara (2020, p.1), ensina-nos e chama a atenção para o atual momento de preocupação na conjuntura nacional brasileira, que vem de encontro à nossa preocupação com os currículos nas escolas brasileiras, visto que

\begin{abstract}
Mistificadores e fanáticos dos mais variados tipos passam a ocupar o mesmo espaço na arena pública que cientistas e estudiosos. Hoje, os "negacionistas" da crise sanitária, da mesma maneira que os negacionistas da ditadura militar brasileira ou da crise climática, passam a desinformar e a reforçar preconceitos em meios de comunicação que deveriam ter por função produzir informação de qualidade.
\end{abstract}

O Juiz do Tribunal de Justiça do Rio de Janeiro, Rubens Casara passou a ser uma grande referência quando o assunto é "fanatismo ideológico". O seu estudo e suas contribuições são importantes no campo educacional. Casara (2020, p.1), destaca que,

\footnotetext{
o fanatismo impede qualquer reflexão. Isso porque para o fanático só existem "certezas". E a existência de dúvidas é fundamental ao desenvolvimento do pensamento e da crítica. Mesmo no campo religioso, a dúvida é fundamental à construção da ideia de fé, enquanto as certezas levam aos fundamentalismos que negam a alteridade. Pode-se dizer que as certezas são inimigas da ciência e do conhecimento. A ideologia, em sua concepção negativa, nubla a percepção da realidade, o que facilita o surgimento de fanatismos. As certezas e as ideias inquestionáveis levam à interdição do debate. Fanatismo e ideologia, portanto, geram posturas anti-intelectualistas e a demonização do conhecimento, vistos como desnecessários e até como perigosos. O fanatismo também leva a fenômenos como o "negacionismo". Isso porque a negação da realidade, da história e da ciência, não raro, é o mecanismo necessário à justificação de uma "certeza", ainda que delirante, como ocorre nos casos de paranoia.
}

As linhas que seguem são uma reflexão, de que nas escolas e nas salas de aula o ensino envolto no improviso, sem aparato científico, com o desprezo dos valores e da cultura, onde tudo é negociável, descartável e infinito, não serve para as crianças e "as juventudes". Urge, que nossos alunos precisam de um tratamento firme, com ciência e tecnologia,

\begin{tabular}{|l|l|l|l|l|}
\hline Q & Anista & n. 19 & Agosto - Dezembro 2020 & p. $239-255$ \\
\hline
\end{tabular}


humanizado, com sonhos e projetos, como pessoas, e, não como objetos descartáveis. Percebese ainda a destruição da razão como projeto. O percurso formativo para muitos políticos não tem importância. Assim, sobra-lhes a mentira e a blasfêmia. Precisamos superar esses péssimos exemplos, no atual momento da pandemia da Covi-19 e da crise econômica e educacional vivenciado no Brasil, para investir mais nas escolas, nos professores e na educação.

\section{O Novo FUNDEB e o Salário dos Professores: economia, saúde e futuro da educação!}

No correr da presente pandemia da Covid-19, o Ministério da Educação e Cultura (MEC) não mostrou capacidade e está sendo ineficaz para traçar metas e diretrizes para um possível retorno às aulas em fins de 2020 ou inícios do ano de 2021. A crise na educação brasileira, aprofundada pela pandemia, com o fechamento das escolas de forma muito repentina, agravada pela falta de gestão e liderança do MEC, fez com que houvesse muito improviso, insegurança e desorientação nas Secretarias da Educação Pública Brasileira.

A sociedade brasileira sentiu profundamente o desprezo pela ciência, tecnologia e conhecimento. A maioria das escolas de Santa Catarina, conforme dados apresentados aos professores em "Live" da Secretaria de Estado da Educação, esforçam-se muito no ensino remoto. A Educação a Distância (EAD) é um exemplo e merecedora de elogios. Sabemos, no entanto, que o ensino presencial é insubstituível. A política brasileira não tem permitido que nas redes públicas houvesse um adequado planejamento e uma coordenação e reordenação de currículos. O MEC com seguidas trocas dos seus Ministros, continua na contra mão, engatinhando e desorientado nos investimentos da Educação Básica, nas Universidades Federais e nos investimentos da ciência e tecnologia, com falta de recursos para as Bolsas de Estudos, na Graduação e Pós Graduação, com destaque aos Cursos de Mestrado, Doutorado e Pós-Doutorado.

No final deste ano, ou no início de 2021, no possível retorno às aulas presenciais nos espaços físicos das Unidades Escolares, a sociedade espera que as redes públicas estejam bem preparadas para um momento único na história recente da humanidade, num mundo conectado em redes. O currículo é a ferramenta que deve ser o norteador da prática e da atividade do professor em sala de aula. É esperada a continuidade no engajamento para a concretização das competências gerais estabelecidas pela BNCC e seus trabalhos organizados

\begin{tabular}{|l|l|l|l|l|}
\hline Qevista Dialectus & Ano 9 & n. 19 & Agosto-Dezembro 2020 & p. 239-255 \\
\hline
\end{tabular}


em cada Estado. Para que as competências se concretizem ao logo do percurso da Educação Básica, é preciso que todos se responsabilizem: professores, alunos, pais, gestores, políticos e governantes. Espera-se uma melhor valorização da ciência, tecnologia, cultura e valorização profissional dos educadores brasileiros da Educação Básica.

Esperamos com grande expectativa a "revolução na educação brasileira". Esta deve incluir neste momento a tão sonhada valorização dos profissionais da educação. A Lei do Piso nacional, o Plano Nacional da Educação, o Currículo Base da Educação Infantil e do Ensino Fundamental do Território Catarinense e a Proposta Curricular de Santa Catarina, são exemplos que legitimam um salário mais justo e um plano de carreira a ser cumprido, não apenas em Santa Catarina mas em todo o espaço do território nacional. O Fundo de Desenvolvimento da Educação Básica (FUNDEB), com suas novas equações e (re)adequações, aprovado em definitivo, precisa ainda ser melhor compreendido, para entendermos se é de fato dali que vai sair uma remuneração mais digna aos professores da Educação Básica. O FUNDEB, paralelamente com a Lei do Piso Nacional nunca teve verdadeira sintonia nos diferentes Estados e Municípios Brasileiros, sendo parcialmente cumprido. Poucos são os Estados e Municípios que cumprem integralmente a Lei do Piso e o Plano de Carreira do Magistério Público.

Um país rumo ao desenvolvimento, que remunera bem seus professores é outro nível de cultura. Seria outro nível se isso fosse uma realidade no Brasil. Qual nada. Estamos muito atrasados. Momentaneamente nenhuma grande revolução em vista. Os professores estão desnorteados e a educação não a atenção merecida. O autor Marx (2018, p. 155), ensina-nos que

uma classe oprimida é a condição vital de qualquer sociedade baseada no antagonismo das classes. A libertação da classe oprimida implica, portanto, necessariamente a criação de uma sociedade nova. Para que a classe oprimida possa libertar-se, é necessário que os poderes produtivos já adquiridos e as relações sociais existentes não possam mais existir lado a lado. De todos os instrumentos de produção, o maior poder produtivo é a própria classe revolucionária.

A cultura de remunerar mal os professores e profissionais da educação é histórica no Brasil. Quantos decênios, com planos e metas, com belas teorias, jogadas ao léu. Pois para os professores não. Faltou vontade política. O Estado não é por acaso uma "comunidade ilusória”, no dizer de Chagas (2012, p. 43). Isso vem de encontro com a afirmação de Marx

\begin{tabular}{|l|l|l|l|l|}
\hline Qevista Dialectus & Ano 9 & n. 19 & Agosto-Dezembro 2020 & p. 239-255 \\
\hline
\end{tabular}


(2018, p. 155), ao ressaltar que "a condição de libertação da classe trabalhadora é a abolição de qualquer classe, como a condição de libertação do terceiro estado, da ordem burguesa, foi a abolição de todos os estados e de todas as ordens". Eis que a classe dos professores, precisa posicionar-se e trabalhar de forma associativa com sindicatos que a representam. Sozinhos, isolados, não nos libertamos.

Objetivamente ao longo da história, ao pagar salário aos professores, a intenção do governo sempre foi economizar. No Brasil, os professores da Educação Básica das diferentes redes públicas recebem muito mal. A rede particular da Educação Básica também remunera mal; a exceção são alguns colégios tradicionais das capitais e grandes centros urbanos; mas estes também ao longo da história foram nivelando os salários muito próximo às remunerações pagas pela rede pública de ensino.

A maioria das Universidades particulares de ensino, também remuneram mal os seus professores, pois tem como parâmetro e mensura os péssimos salários pagos na Educação Básica. Ao melhorarmos o salário na Educação Básica, promessa do Novo FUNDEB, podemos "revolucionar" o salário do professor no Brasil como um todo, tornando-o mais justo em todos os níveis. Ganha a ciência, a tecnologia e a pesquisa. Ganha a educação em qualidade, com profissionais mais motivados.

O autor Chagas (2012, p.43), chama a atenção em seu estudo, do homem que está despojado da sua existência real, afirmando que,

o Estado moderno faz abstração do homem real e só o satisfaz de forma imaginária, abstrata. Tal Estado não pode, pois, suprimir as raízes da fragmentação e da ilusão humana; ele é, antes, a fonte da religiosidade, à medida que ele aparece, agora, como uma comunidade ilusória, corno um universal abstrato, tal como o Deus cristão, como um ser ilimitado, todo poderoso, sem o qual o sujeito não pode subsistir.

O Brasil perde, conforme estatísticas recentes divulgadas pela Organização das Nações Unidas (ONU), para a maioria dos países da América Latina, com investimentos nos salários dos professores e em investimentos com alunos na Educação Básica. Se formos para a América do Norte, Japão, Tigres Asiáticos e Europa, nossa posição cai vertiginosamente em remuneração aos professores da Educação Básica.

\begin{tabular}{|l|l|l|l|l|}
\hline Qevista Dialectus & Ano 9 & n. 19 & Agosto-Dezembro 2020 & p. 239-255 \\
\hline
\end{tabular}


A atual crise da pandemia do Covid-19, ensinou-nos que o Brasil precisa investir urgentemente em escolas, nos alunos, nos professores e em tecnologias educacionais, com destaque aos computadores, internet e Laboratórios de Informática. Com relação a este aspecto, Rambo (2020, p. 36), enfatiza que

A cultura virtual dos Laboratórios de Informática, da rede estadual catarinense deixam a desejar. Contrapondo às contas Google dos professores, "temos poucas nuvens", quando falamos em Laboratórios de Informática nas escolas da Rede Pública Estadual Catarinense. Temos sombras, quando olhamos o presente e o futuro a curto prazo na área das tecnologias, visto que as escolas não possuem nem sequer professores coordenadores desses ambientes de laboratório. Como todo laboratório, é um ambiente que exige manutenção, aprimoramento técnico, preparo, cuidado e orientação. Por ser das tecnologias, a sala da internet e dos computadores requer professor treinado.

Os professores e alunos da Rede Pública no Brasil, possuem dificuldades financeiras em aplicar em tecnologias de ponta para o seu uso pessoal. Com o atual salário, a maioria dos professores da Educação Básica não possuem condições em instalarem na sua residência tecnologias boas como internet de banda larga, assinatura online de bons programas na sua área de formação ou TV Digital por assinatura, ou mesmo um computador que acompanhe a evolução das tecnologias. Numa recente pesquisa sobre a remuneração dos professores, o autor Matijascic (2017, p. 34), como técnico do Ipea, descreve sua pesquisa, afirmando que,

a remuneração dos professores é relativamente baixa em um contexto nacional e varia bastante entre regiões e, mais ainda, por local de residência e tipo de empregador. A consolidação de uma nova realidade, na qual o salário médio será equivalente à média dos profissionais com nível superior completo, deve mudar essa realidade para melhor, mas a heterogeneidade no Brasil tende a persistir. Por um lado, essa heterogeneidade se daria pelo fato de a remuneração do mercado de trabalho apresentar essa marca ao longo do Brasil. Nesse sentido, se o perfil de remuneração dos professores da educação básica se tornar mais homogêneo ao longo do Brasil, sua situação será de destaque no interior do país e nas regiões menos desenvolvidas, pois os níveis médios de renda dessas cidades ou regiões é menor. Já nas regiões mais desenvolvidas, a disparidade pode continuar elevada, pois a presença de mercados laborais mais dinâmicos demanda mais profissionais com maiores níveis de instrução. Por outro lado, propor salários com diferenciação regional pode marcar uma postura de manutenção da desigualdade que atinge o Brasil.

\begin{tabular}{|l|c|c|c|c|}
\hline Qevista Dialectus & Ano 9 & n. 19 & Agosto - Dezembro 2020 & p. $239-255$ \\
\hline
\end{tabular}


Em países desenvolvidos, o professor é um dos primeiros profissionais a ter o acesso às tecnologias digitais, para oferecer mais ao aluno na aprendizagem. No Brasil, o professor e os alunos da Educação Básica sofrem por serem os últimos. Sofrem nas escolas pela péssima qualidade dos equipamentos, multimeios, internet e computadores de péssima qualidade. Além disso, sofrem nas suas residências, por não acompanharem a evolução dos equipamentos, tecnologias e a internet, pela falta de condições financeiras para adquiri-los, dificultando a pesquisa, a comunicação e a clareza dos métodos necessários para a aprendizagem. Sobre a situação dos professores fora das escolas, o autor Matijascic (2017, p.35), destaca ainda que "existem professores que se inserem em condições de trabalho mais frágeis, e isso implica uma situação familiar dotada de carências e que requer atenção por parte dos formuladores de políticas públicas, ainda que isso seja de limitada envergadura".

O atual piso salarial do professor no Brasil, conforme levantamento da Organização para Cooperação e Desenvolvimento Econômica (OCDE), divulgado em 2019, mostra os rendimentos do magistério no Brasil nas últimas posições entre os países partícipes da pesquisa. O Quadro 1, a seguir, baseado com os dados levantados pela OCDE, nos dá uma síntese, da distância que separa o Brasil dos países desenvolvidos quanto aos rendimentos de um professor, além de mostrar a média salarial de um professor na Europa.

Quadro 1 - Países, Salário Inicial e o Salário no Topo da Carreira do Professor da Educação Básica no Mundo

\begin{tabular}{|l|l|l|}
\hline \multicolumn{1}{|c|}{ País } & \multicolumn{1}{|c|}{ Salário Inicial } & Salário/Topo da Carreira \\
\hline $1^{\circ}$. Luxemburgo & US\$ 79.551 & US\$ 138.279 \\
\hline $2^{\circ}$. Suíça & US\$ 71.249 & US\$ 109.240 \\
\hline $3^{\circ}$. Alemanha & US\$ 63.866 & US\$ 92.386 \\
\hline Média da OCDE & US\$ 34.943 & US\$ 59.639 \\
\hline Média da Europa & US\$ 33.871 & US\$ 58.736 \\
\hline $40^{\circ}$. Brasil & US\$ 13.971 & Não divulgado \\
\hline
\end{tabular}

Fonte: OCDE. 2019. Adaptação: autor.

É chegado o momento, no qual o cenário político e a (re)organização do MEC, devem fazer o magistério da Educação Básica mais atrativo financeiramente, e, tornar as

\begin{tabular}{|l|l|l|l|l|}
\hline Qevista Dialectus & Ano 9 & n. 19 & Agosto - Dezembro 2020 & p. $239-255$ \\
\hline
\end{tabular}


jornadas de trabalho menos pesadas com condições de trabalho mais dignas. $\mathrm{O}$ trabalho do professor no Brasil, conforme levantamento da OCDE, é muito insalubre. Trabalha em salas de aula pequenas e lotadas, não possui sala ambiente adequada para o preparo de aula, não possui bibliotecas com periódicos e revistas científicas de divulgação atualizadas e permanentes, faltam livros atualizados nas diferentes áreas de formação, faltam banheiros adequados, e a falta de Laboratórios de Informática entre outros. Além disso, a OCDE, mostrou ainda o fato de que muitos professores no Brasil possuem até três empregos para ter um salário digno. Ele não pode se dedicar a uma única escola, ao mesmo grupo de alunos e professores. Além disso, convive pouco com a sua família. Assim, a saúde, o esgotamento, a qualidade de vida e o rendimento desse professor vai caindo gradativamente com o passar dos anos. A Organização Mundial da Saúde (OMS), fez inúmeros alertas nos últimos anos aos países e seus governantes, para tratarem a questão da saúde do professor com mais dignidade. O alerta está aí e não deve passar em branco.

Além do aspecto da saúde, o atual estágio da globalização interfere para na qualidade de vida do professor e trabalhadores em geral, conforme é destacado por Rech (2008, p. 80), visto que, no espectro da globalização atual, impõe -se um estranho estilo ressentido no qual se declara o fim cabalístico da história, do homem, do Estado-nação, da sociedade, do trabalho e dos trabalhadores, das ideologias, da política, dos partidos políticos, do sindicalismo, da democracia, das instituições representativas e dos antagonismos entre as nações e entre as civilizações. Na transição para a futura sociedade numérica e das novas tecnologias, a única noção que escapa à leitura escatológica do fim de tudo é a do homo economicus, do indivíduo isolado de qualquer determinação social cultural e histórica.

No presente ano de 2020, o Sindicato dos Profissionais da Educação de Santa Catarina (SINTE), divulgou um resultado da pesquisa com os profissionais da educação que trabalham na Rede Pública de Santa Catarina. Os resultados são alarmantes, visto que a pesquisa mostrou uma estatística, com muitos profissionais doentes, com excesso de trabalho, profissionais endividados e professores com mais de uma escola ou mais de uma profissão. $\mathrm{O}$ "stress", foi relatado pela maioria dos profissionais entrevistados. Então, porque neste país, não remunerar melhor e atrair os melhores e mais brilhantes jovens formados para a profissão

\begin{tabular}{|l|l|l|l|l|}
\hline Qevista Dialectus & Ano 9 & n. 19 & Agosto-Dezembro 2020 & p. 239-255 \\
\hline
\end{tabular}


de professor, atuando numa escola, com "dedicação exclusiva e salários atraentes"? O desafio não é simples e fácil; mas possível se houver vontade política.

\section{A Educação a Distância no Brasil (EAD) e o Futuro da Educação no Brasil Pós-Pandemia!}

A educação pós-pandemia no Brasil vai continuar sendo definida pela racionalidade neoliberal? Se não for, será uma revolução para a retomada do desenvolvimento. Com relação às previsões ou conclusões sobre o futuro do Brasil, para vencermos os três maiores desafios, sejam na educação, saúde e economia, Casara (2020, p. 2), resume, afirmando que,

O mundo pós-pandemia vai ser definido a partir da resolução de uma questão prévia: a manutenção ou não da racionalidade neoliberal. Insistir na naturalização do modo de pensar e atuar neoliberal, que considera a busca do lucro e de vantagens pessoais o único objetivo "racional", e ao mesmo tempo em que trata as pessoas como objetos negociáveis, pode levar a dois horizontes catastróficos, apresentados como naturais e inevitáveis, como toda manifestação neoliberal.

Nos países em que o pensamento autoritário se instaura sem maiores dificuldades, nos quais o conhecimento e a ciência são demonizados enquanto a violência é sacralizada, as mortes causadas pela covid-19 são tratadas como positividades, da mesma maneira que a eugenia era tratada como uma positividade pelos nazistas no século passado. Com isso, nos países de baixa densidade democrática, haverá o aprofundamento de um paradigma repressivo de governo baseado no poder disciplinar, no obscurantismo e na naturalização de mortes evitáveis em nome dos interesses de poucos.

Na ausência de limites pela sociedade atual, a educação continuará a sofrer pressões e exploração. O poder político e econômico serão grandes freios para a revolução na educação.

Dito de outra forma, Casara (2020, p. 3), acrescenta que,

a racionalidade neoliberal, portanto, fará com que se insista em fazer do Estado um instrumento a serviço do mercado e dos detentores do poder econômico. Assim, será prestado auxílio financeiro a empresários e a instituições financeiras e a liberdade dos cidadãos será restrita em nome do medo da contaminação. Além disso, espaços de intimidade serão eliminados, reatualizando o poder disciplinar e aumentando o controle biopolítico sobre a população.

Mas, diante de um quadro de crise, também se pode construir saídas novas e originais, revolucionárias, a partir de um outro modo de ver e atuar no mundo. Apresentar caminhos alternativos para o mundo pós-pandemia é um desafio, mas também um dever ético. Construir coletivamente um outro mundo possível, em reação ao qual cada pessoa se perceba responsável, ainda é um sonho, mas pode se tornar realidade.

\begin{tabular}{|l|c|c|c|c|}
\hline Qenista Dialectus & Ano 9 & n. 19 & Agosto-Dezembro 2020 & p. 239-255 \\
\hline
\end{tabular}


É chegado o momento que almejamos um mundo pós-pandemia, mais fraterno, solidário e cooperativo. Na educação, o professor é um dos profissionais mais vulneráveis ao Covid-19, e, diante desse quadro, as aulas presenciais não devem reiniciar no presente ano de 2020. O médico Silva (2020, p1.), em entrevista, enfatiza o problema, afirmando que,

contra os mestres pesam basicamente dois fatores, aliás, três, no caso de alguns. O primeiro é que muitos adquirem ou agravam várias doenças no exercício da profissão, como problemas na garganta, doenças respiratórias, hipertensão, diabetes, dores nas costas, esgotamento físico e mental, depressão etc. Isto baixa a imunidade dos mesmos e os torna, naturalmente, muito mais frágeis nessa guerra contra a pandemia.

Ao fator descrito temos mais dois fatores que pesam fortemente contra a saúde do professor, que no dizer de Silva (2020, p.1-2), são motivados, porque,

\footnotetext{
A escolas são espaços naturais de aglomeração, e as salas de aula mais ainda. Já imaginou uma professora ou professor numa sala com 20,30, 40 ou mais alunos? Um perigo! Se não estiverem todos muito bem protegidos, o risco de contaminação é enorme.

Um terceiro fator também importantíssimo é que muitos professores têm mais de 50 anos e já estão debilitados por causa de outras doenças. Idade e doenças preexistentes compõem um coquetel que pode ser mortal para eles, caso se contaminem com coronavírus.
}

O retorno às aulas, conforme recomendam a maioria dos médicos comprometidos com a pesquisa, ciência e saúde no Brasil e da Organização Mundial da Saúde (OMS), não é aconselhado por ainda ser arriscado demais, quando o assunto é retorno às aulas presenciais. A segurança, portanto, é a torcida pelo advento de uma vacina ou um medicamento eficiente no combate ao Covid-19.

No mês de maio de 2020, o movimento "Todos pela Educação", apresentava um texto com o título "Educação na Pandemia: o retorno às aulas presenciais frente à Covid-19". O texto reunia as principais mensagens de alerta ao Governo Federal e ao Ministério da Saúde. O teor do texto que levou em consideração dificuldades, crises e desastres enfrentados por outros países, experiência em gestão pública pós-crise, a serem levados em consideração com seriedade pelo Brasil, podem ser resumidos, conforme Cardoso (2020, p.2), em três itens essenciais:

\begin{tabular}{|l|c|c|c|c|}
\hline Qevista Dialectus & Ano 9 & n. 19 & Agosto-Dezembro 2020 & p. $239-255$ \\
\hline
\end{tabular}


1. As escolas irão se deparar com desafios que só podem ser enfrentados com apoio de outras áreas;

2. Não será uma "retomada de onde paramos". O plano de ações deve contemplar diversas frentes e demandará intensa articulação e contextualização local;

3. As respostas ao momento atual podem dar impulso a mudanças positivas e duradouras nos sistemas educacionais.

A aprendizagem é um processo e como tal de nada adiantará querer retomar todo o conteúdo não trabalhado em muitas horas, para compensar os dias perdidos presencialmente na Unidade Escolar. Ao retornarmos da pandemia do Covid-19, será essencial focarmos nas competências, habilidades e conceitos científicos essenciais. Não poderemos estar presos demais aos conteúdos programáticos. Na reorganização do calendário escolar e do currículo escolar a criatividade e a flexibilidade são vitais para todos se inserirem bem e se contextualizarem na retomada dos trabalhos, sem sobrecarregarmos demais os alunos com conteúdos como tijolos, que não preparam para o trabalho e cidadania.

\section{Considerações Finais}

A expectativa é de que, terminada a pandemia, os professores e alunos voltarão diferentes ao ambiente escolar, do que quando a deixaram. Devido ao isolamento, sacrifícios, regras, ritmos diferentes de trabalho, descanso, disciplina, ansiedade, cuidados com a higiene, distanciamento entre as pessoas, falta de perspectiva de aumento e valorização salarial e profissional, falta de ânimo, fará com que os profissionais da educação e alunos estejam diferentes, ao menos do ponto de vista psicológico e comportamental. A autora Cardoso (2020, p.2), afirma que "será um novo tempo de acolher os professores e alunos, daí a necessidade de uma abordagem multidisciplinar e intersetorial, envolvendo educadores, médicos, psicólogos, assistentes sociais etc.” Além do mais, será necessário o diálogo da escola e professores com os pais. A presença dos pais na escola, mais do que nunca, participando e interagindo nas atividades e programações, será muito importante. Os núcleos representativos da escola, como, Conselho Deliberativo Escolar, Conselho de Classe Escolar, Professores Regentes, Associação de Pais e Professores (APP), Grêmio Estudantil e Clube de Mães, terão seu papel no diálogo, reorganização, funcionamento e gestão democrática escolar, pós-pandemia do Covid-19.

\begin{tabular}{|l|c|c|c|c|}
\hline Qevista Dialectus & Ano 9 & n. 19 & Agosto-Dezembro 2020 & p. $239-255$ \\
\hline
\end{tabular}


Na Rede Catarinense, a Proposta Curricular de Santa Catarina é uma ferramenta muito importante e que deve e precisa rechear as discussões e os diálogos, por conter importantes eixos norteadores e pressupostos teóricos e metodológicos que orientam os profissionais da educação.

O acolhimento é uma questão de ética, no retorno às aulas, pós pandemia do Covid19. Assim, a responsabilidade e solidariedade serão de fundamental importância para todos se sentirem bem e acolhidos no ambiente escolar. O autor Morin (2012, p.41), ensina-nos que,

\begin{abstract}
as questões chave da ética são a responsabilidade e a solidariedade, duas dimensões inseparáveis, porque se eu me sinto responsável, eu me sinto solidário. E, se eu me sinto solidário, eu me sinto responsável. Solidariedade e responsabilidade implicam, em todos os campos da ação da ética, o restabelecimento da solidariedade responsabilidade e vice-versa. No mundo atual, a tendência dominante de nossa civilização ocidentalizada é a desintegração da solidariedade e também a tendência a uma vida isolada, onde cada uma vive em seu pequeno mundo, em seu setor, com responsabilidade restrita ao seu viver, mas que não pratica uma solidariedade comum.
\end{abstract}

Precisamos, portanto, da solidariedade e acolhimento, para que a evasão escolar não seja ainda maior na Educação Básica. Muito importante será a busca de um trabalho entre a escola e os pais para trazer de volta o aluno evadido. Muito provavelmente haverá a emigração de alunos das escolas particulares para a rede pública de ensino. Com a crise, a classe média perdeu renda, emprego e poder aquisitivo. A rede pública de ensino precisará se desdobrar; com menos recursos, precisará atender mais alunos e superar mais problemas. O aluno pobre está na rede pública de ensino; e é a ele que devemos dar mais como profissionais da educação, se quisermos animá-lo com o "sonho de viver bem", conforme ensina Gadotti (2009, p. 14), e mencionado no correr do texto. A escola como espaço social para a aprendizagem estará valorizada depois da pandemia. O professor voltará mais valorizado pelas famílias, pela dimensão da complexidade que envolveu os pais em lidarem com os filhos nas tarefas escolares. Urge, que o Estado, o MEC e os políticos valorizem o professor com melhores condições de trabalho e salário. A mensagem de Souza (2017, p. 234), não são nada dóceis, mas de extrema urgência, ao afirmar que "a esperança de hoje tem que ser uma adaptação contemporânea do velho chamado aos explorados: os feitos de imbecis de todo país: uni-vos!" Isso deve e pode ser transposto para os professores,

\begin{tabular}{|l|c|c|c|c|}
\hline Qevista Dialectus & Ano 9 & n. 19 & Agosto-Dezembro 2020 & p. $239-255$ \\
\hline
\end{tabular}


sindicatos. Precisamos urgentemente de uma revolução na educação do Brasil, para enfrentarmos melhor e com mais preparo outras pandemias e crises que vierem pela frente.

\section{Referências:}

CAPRA, Fritjof. As conexões ocultas - ciência para uma vida sustentável. Tradução de Marcelo Brandão Cipolla. São Paulo: Cultrix, 2005.

CARDOSO, Beatriz. Desafios Para a Educação Pública Agora e Depois da Covid-19. Disponível em: https://fundacaofhc.org.br/iniciativas/debates/desafios-para-a-educacaopublica-agora-e-depois-da-covid-19 . Fundação FHC, 08 de maio de 2020/transmissão online via Zoom.

CASARA, Rubens. O descuido com a vida no Brasil é um projeto político. Nada tem de natural. Revista Esquinas. Revista Digital Laboratório da Faculdade Cásper Líbero. Entrevista feita por: Letícia Keller, 18 de junho de 2020.

CASTELLS, Manuel. A Sociedade em Redes. A Era da Informação: Economia, sociedade e Cultura, Volume 1. São Paulo: Paz e Terra, 2009. (Tradução de Roneide Venancio Majer com a colaboração de Klauss Brandini Gerhardt).

CHAGAS, F. Eduardo. O pensamento de Marx sobre a Subjetividade. In: CHAGAS, Eduardo F.; RECH, Hildemar Luiz; et. al. (Orgs.). Subjetividade e Educação. Fortaleza: UFC, 2012, p. 37-62.

CHILDE, Gordon. A Evolução Cultural do Homem. 5.ed. Tradução de Waltensir Dutra. Zahar: Rio de janeiro, 1986.

CLAVAL, Paul. A Geografia Cultural. 2. Ed. Florianópolis: UFSC, 2001. (Tradução de Luíz Fugazzola Pimenta e Margareth de Castro Afeche Pimenta).

CLAVAL, Paul. Terra dos Homens - a geografia. Tradução de Domitila Madureira. São Paulo: Contexto, 2010.

COUTINHO, Carlos Nelson (Org). O leitor de Gramsci - Escritos escolhidos: 1916-1935. Rio de Janeiro: Civilização Brasileira, 2011.

GADOTTI, Moacir. Educar para a Sustentabilidade - Uma contribuição à Década da Educação para o Desenvolvimento sustentável. São Paulo: Instituto Paulo Freire, 2009 (Série Unifreire 2). 12.

MARX, Karl. A Miséria da Filosofia (Resposta à Filosofia da Miséria de Proudhon). Tradução de: Paulo Roberto Banhara. São Paulo: Lafonte, 2018.

\begin{tabular}{|l|l|l|l|l|}
\hline Q & Anista & n. 19 & Agosto - Dezembro 2020 & p. $239-255$ \\
\hline
\end{tabular}


MATIJASCIC, Milko. Professores da Educação Básica no Brasil: Condições de Vida, Inserção no Mercado de Trabalho e Remuneração. Texto para Discussão no 2304. Brasília: Ipea, 2017.

MARINI, Eduardo. Alfabetização digital se torna obrigatório para as escolas. Revista Educação (Online), edição 259, 3 de jul. de 2019. Acesso em: 16 de abril de 2020.

MORIN, Edgar. Ciência com Consciência. 7.ed. Rio de Janeiro: Bertrand Brasil, 2003. (Tradução de Maria D. Alexandre e Maria Alice Sampaio Dória).

MORIN, Edgar. Os sete saberes necessários à educação do presente. In: MORAES, Maria Cândida; DE ALMEIDA, Maria da Conceição (Orgs.). Os Sete Saberes Necessários à Educação do Presente - Por Uma Educação Transformadora. Rio de Janeiro: Wak, 2012, p. $33-45$.

PINTO, João Roberto Lopes. Economia Solidária - De volta à arte da associação. Porto Alegre: UFRGS, 2006.

RAFFESTIN, Claude. Por uma Geografia do Poder. São Paulo: Ática, 1993.

RAFFESTIN, Claude. Territorializzazione, desterritorializzazione, riterritorializzazione e informazione. In: TURCO, Angelo. Regione e regionalizzazione. Milano: Franco Angeli, 1984, p. 69-82.

RAMBO, Nestor Francisco. A Educação em Rede em Época de Pandemia: Algumas Nuvens e Muitas Sombras. In: SCHÜTZ, Jenerton Arlan; MAYER, Leandro (Orgs.). Vozes Contemporâneas da Educação. Ilustração: Cruz Alta, 2020, p. 27-49.

RECH, Hildemar Luiz. Geoestratégias, estado e globalização econômica. In: SOUZA, Antônia de Abreu, et. al. Trabalho, Capital mundial e formação dos Trabalhadores. Fortaleza: SENAC/CE/UFC, 2008, p.63-83.

SANTA CATARINA. Secretaria de Estado da Educação. Currículo Base da Educação Infantil e do Ensino Fundamental do Território Catarinense. Florianópolis: COAN, 2019.

SANTA CATARINA. Secretaria de Estado da Educação. Proposta Curricular de Santa Catarina - Formação Integral na Educação Básica. Forianópolis: SED, 2014.

SANTA CATARINA. Secretaria de Estado da Educação. DIRETRIZES 3 ORGANIZAÇÃO DA PRÁTICA ESCOLAR DA EDUCAÇÃO BÁSICA. Florianópolis: SED, 2001.

SANTOS, Milton. TÉCNICA, ESPAÇO, TEMPO - Globalização e Meio Técnico-Científico Informacional. 3.ed. São Paulo: Hucitec, 1997.

\begin{tabular}{|l|c|c|c|c|}
\hline Qevista Dialectus & Ano 9 & n. 19 & Agosto - Dezembro 2020 & p. 239-255 \\
\hline
\end{tabular}


SANTOS, Milton; SILVEIRA, Maria Laura. O BRASIL - Território e Sociedade no início do século XXI. 11.ed. Record: Rio de Janeiro/São Paulo, 2008.

SOUZA, Jessé. A Elite do Atraso - da Escravidão à Lava jato. Rio de Janeiro: Leya, 2017.

\begin{tabular}{|l|l|l|l|l|}
\hline Q Revista Dialectus & Ano 9 & n. 19 & Agosto-Dezembro 2020 & p. 239-255 \\
\hline
\end{tabular}

